\title{
Analysis on the Operation Efficiency of China's Marine Transportation Industry and Its Influencing Factors
}

\author{
Wu Shujuan, Lu Junming, Xiao Jianhua \\ Wuyi University \\ Jiangmen, Guangdong Province, 529020 \\ Industrial and Commercial Bank of China branch in Foshan \\ Foshan, Guangdong Province, 528000
}

\begin{abstract}
China's marine transportation industry needs to change its current operation mode and improve economic efficiency, so that it can survive in the turbulent market. Based on the DEA model, it measures the eleven coastal provinces and cities' marine transportation industry efficiency by taking the number of berths and their berths as input indicators and the coastal port cargo as throughput, international standard tank throughput and passenger throughput as output indicators. Then, a regression analysis of China's marine transportation industry and its influencing factors is done by using EVIEWS software. It is found that the operation efficiency of China's marine transportation industry is good, but still needed to be improved. The investment in fixed assets of the coastal transportation industry and the container capacity of the wheel barge and its power have a positive effect on the operation efficiency of the marine transportation industry. Measures in the fields of ports, fleets, employees and waterways should be taken to solve those problems.
\end{abstract}

Keywords-DEA mode; Marine transportation industry; Operating efficiency; Influencing factors

\section{INTRODUCTION}

Marine transportation industry is one of the most economic benefits ocean industries in recent years, which is an important part of Chinese marine economy, and it is the benchmark of the shipping market of the world, of which marine cargo transportation is the major part. With the development of economic globalization, the marine transportation market was dropping in the bottom. The indicators of idle large freights and the occupation rate of cargo ship both indicate the phenomenon that supply exceeds demand [1]. In order to cope with the market fluctuation, mergers and acquisitions in the industry always happened. In year 2016, China COSCO Group (COSCO) and China Shipping (CSCL) merged and reorganized to form COSCO Group; United Arab Shipping Company(UASC) and Herbert Rover Shipping Company (HPL) were reorganized [2]; Hanjin Shipping (HANJIN), a leading Korean shipping company, applied for asset restructuring; France's CMA merged of Australian National Lines (ANL) with US Line (USL) across the Pacific route service into the American Presidential Lines (APL); Nippon Yusen Kaisha (NYK), Kawasaki Line (K-LINE) and Mitsui O.S.K. Lines (MOL) confirmed that the business will be reorganized [3-4].
Based on the situation, the Chinese shipping market will be affected by the harsh external environment. China's marine transportation industry needs to change the current mode of operation, and improve economic efficiency, so as to survive the turbulent market. Therefore, the operation efficiency of the maritime industry should been paid much attention to. Lin W C, Liu C F, Chu C W (2005) used the Data Envelopment Analysis (DEA) method to evaluate the operation efficiency of 14 shipping companies by using financial indicators [5]. In the study of inland areas, Jian L, Zhilan ZI, Gao H (2011) also used DEA's C2R model to analyze the technical efficiency of 12 shipping companies [6]. Weilong YE (2010) evaluates the cost efficiency of China's listed ports and shipping companies based on the cost-efficiency evaluation model of stochastic frontier analysis (SFA), indicating that although the cost efficiency levels of these ports and shipping companies has risen year by year, measures should be taken to expand the source of income, reduce expenditure, and control the overall cost [7]. For the analysis of the operation efficiency of domestic regional marine transportation industry, Lv KJ, Fan BJ, Li WM (2014) used DEA model to evaluate the efficiency of Shanghai shipping industry from year 2000 to 2010, and through cross-evaluation method and Mulquist DEA method. Results show that the Shanghai should be transited to the government-led shipping center, and also it should focus on promoting the shipping information technology, high-end shipping services and the risen the shipping employees' professional level [8].

The existing literature shows: first, the evaluation method is generally DEA method or SFA model; second, the operation indicators are always chosen as input and output indicators; third, the data used includes listed companies' financial data and statistical data. However, the existing literature focus mainly on the assessment of the efficiency of the marine transportation industry. It has not further explored the impact of marine transport industry factors, which makes the countermeasures and suggestions proposed are not well-directed. Therefore, based on the evaluation of the efficiency of China's marine transportation industry, this paper further analyzes its influencing factors and puts forward a set of targeted countermeasures to promote the development of China's marine transportation industry. 


\section{SELECTION OF OPERATIONAL EFFICIENCY EVALUATION METHOD AND ITS EMPIRICAL ANALYSIS}

\section{A. Method selection}

At present, the efficiency analysis method can be divided into two types: non-frontier and frontier analysis methods. DEA is a non-parametric method of the frontier analysis method, created by Charnes and Copper [9] and so on, it is also a method of evaluating the relative efficiency of multiple "units (hereinafter referred to as DMU)" using mathematical models. The DEA approach is an assessment of relative efficiency. It ignores the specific operation within a system, but mainly study the input and output efficiency ratio of the system by comparing and evaluating the relative performance of the system. This is an indirect evaluation of the efficiency of the marine transportation industry. It ignores the differences in the operations of the marine transportation industry, and effectively evaluates inputand-output efficiency of different models to achieve the purpose of the study.

\section{B. Evaluation indicators selection}

In view of the research purpose and quantitative analysis method, this paper takes the number of berths in coastal ports, berth length of coastal ports as input indicator, coastal port cargo throughput, coastal port international standard container throughput, coastal passenger throughput as output indicator. And constructs an evaluation indicators system of the operation efficiency of marine transportation industry in coastal areas, as shown in Table 1.

TABLE I.

THE INPUT-OUTPUT INDEX OF THE CHINESE MARINE TRANSPORTATION EFFICIENCY

\begin{tabular}{|c|c|c|c|}
\hline Indicator type & Indicator name & variable & unit \\
\hline \multirow{2}{*}{ Input indicators } & Coastal berths & $\mathrm{M}$ & individual \\
\cline { 2 - 4 } & Coastal berth length & $\mathrm{N}$ & Million meters \\
\hline \multirow{2}{*}{ Output indicators } & Coastal port cargo throughput & $\mathrm{O}$ & Million tons \\
\cline { 2 - 4 } & Coastal port international standard box throughput & $\mathrm{P}$ & Million TEU \\
\cline { 2 - 4 } & Coastal Passenger Throughput & $\mathrm{Q}$ & Million people \\
\hline
\end{tabular}

\section{Data Sources}

This paper chooses 11 coastal provinces and cities of China as DMU. As part of the data shows that the overall indicators of waterway shipping, and water transportation also covers the composition of non-maritime shipping. In order to remove nonmaritime shipping part in waterway shipping, the error is minimized and the paper only selects the data on indicators for coastal or oceanic parts. Data is from the provincial and municipal statistical information website (from year 2011-2015) and the People's Republic of China Ministry of Transport website (http://www.moc.gov.cn/).

\section{Result analysis}

Operation efficiency of the China's coastal provinces and cities in year 2010-2015 is calculated by DEAP 2.1, the results of which is shown in Table 2. A value of 1 indicates valid efficiency and a value of 0 indicates non-effective efficiency. Results show:

(1) During the period of investigation, the operation efficiency of marine transportation in China's coastal areas is relatively good, and the average operating efficiency is 0.82 . The technical efficiency values of the provinces and cities, such as Hebei and Shanghai, equals to 1, indicating that the provinces and autonomous regions of high DEA efficiency account for $36.4 \%$ of China's coastal areas, while the DEA efficiency value of the remaining provinces and cities is lower than 1, indicating that other provinces and cities are not of DEA valid value. Shandong Province and Liaoning Province are 0.97 and 0.91 respectively, very close to the efficient value of DEA, which account for $18.2 \%$ of China's coastal provinces and cities. The remaining provinces and cities rank in turn followed by
Guangdong, Jiangsu, Zhejiang, Fujian and Guangxi. They do not show much of the gap. From the other side, they also reflect an upward trend of China's marine transportation industry. But there is a slight polarization trend among these areas. The operating efficiency of marine transportation industry some provinces and cities, especially the provinces and cities south to the Yangtze River, needs to be improved.

(2) China's southeastern coast area is the most developed region of contemporary China, but the empirical results show that the pure technology efficiency of the provinces along the southeast coastal area is lower than the average of 0.82 . Even though their foreign trade is the top 10 in China, whose the foreign trading share leads in more than $70 \%$ of the country's provinces and cities. The economic efficiency of the marine transportation industry of those areas do not play a good lead. The most important reason is that the output is redundant and thin. Guangxi Province is a very good example. It locates to south of the South China Sea, east of Guangdong Province, but it did not use its own geographical advantages, also it did not learn from the successful development experience in Guangdong Province to develop marine transport industry, causing marine transport efficiency low.

(3) The southeastern coastal areas is also an important window for the opening up. Guangdong and Shanghai dominate in China's marine economy. They are also very strong in economic growth and account for more than $50 \%$ of the total foreign trade provinces. But Guangdong Province has not reached the average provincial technology efficiency. Since the reform and opening up, the degree of opening up in Guangdong Province is very high. However, after the policy began to tilt to the Yangtze River Delta, the advantages of Guangdong Province 
gradually weakened. The marine transportation industry of Guangdong Province falls behind the Yangtze River Delta region, which is one of the typical cases. It can be seen that the growth of operation efficiency is an important driving force for the steady progress of the industrial economy.

TABLE II. CHINA'S MARINE TRANSPORTATION INDUSTRY OPERATION EFFICIENCY EVALUATION RESULTS

\begin{tabular}{|c|c|c|c|c|c|c|c|c|c|c|c|}
\hline & Liaoning & Hebei & Tianjin & Shandong & Jiangsu & Shanghai & Zhejiang & Fujian & Guangdong & Guangxi & Hainan \\
\hline 2011 & 0.898 & 0.991 & 1 & 0.986 & 0.698 & 1 & 0.635 & 0.593 & 0.842 & 0.275 & 0.993 \\
\hline 2013 & 0.900 & 0.989 & 1 & 0.968 & 0.759 & 1 & 0.658 & 0.674 & 0.821 & 0.385 & 0.974 \\
\hline 2014 & 0.908 & 0.999 & 1 & 1 & 0.789 & 0.974 & 0.732 & 0.665 & 0.763 & 0.334 & 1 \\
\hline 2015 & 0.919 & 1 & 1 & 0.95 & 0.712 & 1 & 0.618 & 0.613 & 0.759 & 0.339 & 1 \\
\hline
\end{tabular}

\section{ANALYSIS OF INFLUENCING FACTORS OF EFFICIENCY}

\section{A. Variable selection}

Factors that can affect the efficiency operation of marine transportation industry are complex and diverse, including factors such as ship crafts, port construction, waterway conditions, loading and unloading efficiency, scientific and technological input and the levels of employees. Under the principle of multi-faceted and omni-directional, taking the origin and acquisition of data into account, this paper selects the investment volume of fixed assets in coastal marine transportation, the container bunker and its power as variables that affect the efficiency of marine transportation industry.

\section{B. Build models and data sources}

In order to test the influencing factors of the operational efficiency of China's marine transportation industry, a panel data of 11 provinces and cities in China's coastal areas from year 2010 to 2015 is validated by using the general economic growth research model. On the basis of previous empirical analysis of China's marine transportation industry, a multiple regression equation was created as follows:

$$
\mathbf{y}=\mathbf{c}+\beta 1 \mathrm{tze}+\beta 2 \mathrm{jzx}+\beta 3 \mathrm{gl}+\mu
$$

Among: $Y$ indicates the operation efficiency of marine transportation industry; tze represents investment volume of the fixed assets of coastal traffic; jzx represents wheel barge container; gl represents power of barge ship, $\beta 1, \beta 2, \beta 3$ represents the variable regression coefficient; $c$ is the constant term; $\mu$ is for random variables.

The data is mainly from the Ministry of Transport website (http://www.moc.gov.cn/) and the national statistical yearbook.

\section{Empirical Analysis}

Use Eviews6.0 for regression analysis. First of all, the data is non-dimensionalizd, and then tested through unit root test, and co-integration test. In the model, the accompanying probability $\mathrm{p}$ of Levin, Lin \& Chu, ADF, PP, etc. of the variables in the model is less than 0.1, and the assumption of GE's unit root is rejected. The R-squared and Adjusted R-squared models are in the range of $0.99-1$, indicating that the fitting effect is very good. The model is tested by F-statistic. The investment volume of fixed assets in coastal traffic, the container capacity of wheel barge and its power have an impact on the operation efficiency of marine transportation industry at a significant level of $5 \%$. The empirical result is as follows:

$$
\begin{array}{r}
\mathrm{y}=0.07+0.0274 \mathrm{tze}+0.0895 \mathrm{jzx}+0.0456 \mathrm{gl} \\
(*) \quad(*) \quad(* *) \\
(20.76) \quad(24.25) \quad(18.52)
\end{array}
$$

We can see from the regression coefficients of the fixed assets of coastal transportation investment, wheel barge container and wheel barge power are positive, which shows that the three factors positively correlated with the operation efficiency of the marine transport industry. It indicates that it can help to increase the operation efficiency of marine transportation industry by increasing the amount of fixed assets investment, the capacity of barge container and the improvement of the power of the barge in coastal areas.

\section{CONCLUSIONS AND COUNTERMEASURES}

\section{A. Conclusion}

this paper takes 11 provinces and cities in China's coastal areas as the objects of evaluation, use DEA model as the evaluation and analysis method, and select the coastal ports, berths and the number of berths as the input indicators, coastal port cargo throughput, coastal port international standard container throughput and coastal passenger throughput as output indicators. The coastal areas of China's marine transportation industry economic efficiency was measured, and then use the EVIEWS6.0 software for the regression analysis to find out the factors may affect the economic efficiency of China's marine transport industry. It concludes as follows: (1) The operation efficiency of China's marine transportation industry is relatively good; (2) the operation efficiency of marine transport industry in Hebei, Tianjin, Shanghai and Hainan is DEA efficiency; Shandong Province and Liaoning Province are also among the best; (3) Pure technology efficiency of some provinces and cities in the southeast coastal areas is not high comparatively, the reason for which may be the resources input is over-invested while the output is too little. (4) The regression coefficients of fixed assets of coastal traffic, the weight of wheel barge container and wheel barge are positive, which shows that the three factors are positively related to the transportation efficiency of marine transportation industry. 


\section{B. Countermeasures}

1) Vigorously strengthen the port construction, in-depth implementation of the "port first" approach

Coastal ports are the basic transportation facilities of the marine transportation industry, but also the benchmark for development of the maritime transportation industry. Coastal provinces and cities should make a reasonable port development planning, and carry out major port investment plans, based on local conditions. Also, they should expand the size of the ports reasonably, improve and update port infrastructure equipment, and actively equip the ports with modern facilities. Taking the Yangtze River Delta as model, other provinces and cities should strengthen the construction of port groups, especially in the aspects of port planning, port performance. Only by speeding up the modernization of the ports, and improving the mode of operation, the coastal provinces and cities can actively respond to the harsh world shipping market environment, understand the crisis-and-opportunities coexist situation, seize the development opportunities, improve the port's comprehensive service level, and solve the "There are ships but no ports" problem.

2) Strengthen the construction of the fleet, improve the technical level of the fleet

Port and fleet is like the left arm of the ocean transportation industry. The port infrastructure should fit the level of construction of the fleet, and the technical content of the fleet should also be in compliance with the port terminal operation. The shipping companies in the coastal provinces and cities should improve the liner shipping system, increase the liner transportation and transportation density according to the situation of that area, increase the number of port containers and increase the working efficiency of the liner transport, speed up the construction of the fleet, properly adjust the fleet structure, strengthen the capacity of the ship to transportation equipment, continuously improve the transportation power and efficiency of the existing fleet, and constantly upgrade the fleet of existing equipment to improve the fleet capacity level. Also, the provinces and cities should strengthen fleet management and transportation scheduling, and strictly require the fleet as a whole to provide excellent transportation services, to strengthen the shipbuilding ability, by learning from the advanced countries experiences, and strive to make China's marine transportation achieve world-class level.

3) Improve the intensity of waterway construction, improve the terminal distribution system

Coastal provinces and cities should rationalize the optimization of waterway design, remediation of existing transport efficiency of low waterways based on their own development. As passenger and cargo transportation is comparatively large, so the efficiency of passenger and cargo transportation should be timely improved. Coastal provinces and cities should reduce the transportation schedule, improve the peripherals and the relevant transportation equipment, and increase investment in technology. Also, hinterland is too narrow, and the port between the hinterland and the inland link is not smooth. So coastal provinces and cities must strengthen the hinterland infrastructure construction, broaden the hinterland, improve the inland transportation network, speed up the construction of highway and railway, improve the port distribution system, so that the port resources can match the marine transportation system timely and efficiently. The coastal provinces and cities should play a leading role in marine transportation economy, in the early stage of land-and-sea cooperation and the co-development goals.

4) Speed up the pace of investment in science and technology, increase the construction of intelligent ports

The intelligent port is the concept of intelligent integration of the logistics port in recent years, which integrates the logistics supply and demand into the port collection and distribution. The main characteristic is the use of the new information technology for the contemporary logistics to provide safe, efficient, high quality, excellent service and intelligent port management. The main role is to increase the scientific research on the marine transportation industry, which is conducive to the construction of intelligent ports, to speed up the operational efficiency, to strengthen the building of ports as a smart E-port, cloud computing, large data and mobile Internet investment and construction, and further enhance the large-scale container yard and large data computing equipment, intelligent upgrade architecture. The provinces and cities should adjust and upgrade to increase the port intelligent logistics equipment and become technology-intensive intelligent port as soon as possible.

\section{REFERENCES}

[1] Tang Guozhi. Haikou Port as the core of Hainan Province to accelerate the integration of port resources [J]. China's port, 2017, (03): 22-24.

[2] Chen Xiangyan. Hanjin maritime bankruptcy storm [J]. Maritime overview, 2016 (9): 10-12.

[3] Xu Yi. Shipping industry need to inject fresh blood [J]. Shipping information, 2016 (5): 25-25.

[4] Xu Jianhua. Three heroes common adventure in the sea [J]. China ship inspection, 2017 (1): 22-27.

[5] Lin W C, Liu C F, Chu C W. PERFORMANCE EFFICIENCY EVALUATION OF THE TAIWAN'S SHIPPING INDUSTRY: AN APPLICATION OF DATA ENVELOPMENT ANALYSIS [J]. Proceedings of the Eastern Asia Society for Transportation Studie, 2005:467--476.

[6] Jian L, Zhilan Z I, Gao H. Performance evaluation of China's listed shipping companies operation based on model of DEA [J]. Journal of Dalian Maritime University, 2011.

[7] Weilong Y E. Evaluation on cost efficiency of listed port and shipping companies [J]. Journal of Shanghai Maritime University, 2010.

[8] Lv K J, Fan B J, Li W M. Study on Efficiency Evaluation of Shanghai Shipping Industry [J]. Advanced Materials Research, 2014, 869-870(869870):315-321.

[9] Charnes A, Cooper W W, Rhodes E. Measuring the efficiency of decision making units [J]. European Journal of Operational Research, 1978, 2(6): 429-444. 